\title{
Clinical Leadership in Mental Health Nursing: The Importance of a Calm and Confident Approach
}

\author{
Gary Ennis, BSc, Brenda Happell, RN, RPN, BA(Hons), Dip Ed, BEd, MEd, PhD, and \\ Kerry Reid-Searl, BHIth Sc (UCQ), MClin Ed, (UNSW), PhD, MRCNA, FCN
}

\begin{abstract}
Gary Ennis, BSc, is a Research Higher Degree Student, Institute for Health and Social Science Research, Centre for Mental Health Nursing Innovation, and School of Nursing and Midwifery, Central Queensland University, Rockhampton, Queensland, Australia, and is a Senior Nurse, North Western Mental Health, Melbourne, Victoria, Australia; Brenda Happell, RN, RPN, BA(Hons), Dip Ed, BEd, MEd, PhD, is Engaged Research Chair Mental Health Nursing, Institute for Health and Social Science Research, Centre for Mental Health Nursing Innovation, and School of Nursing and Midwifery, Central Queensland University, Rockhampton, Queensland, Australia; and Kerry Reid-Searl, BHlth Sc (UCQ), MClin Ed, (UNSW), PhD, MRCNA, FCN, is Assistant Dean of Simulation, School of Nursing and Midwifery, Central Queensland University, Rockhampton, Queensland, Australia.
\end{abstract}

Search terms:

Leadership, mental health, nursing

\section{Author contact: \\ g.ennis@cqu.edu.au,b.happell@cqu.edu.au, with a copy to the Editor: gpearson@uchc.edu}

\section{Conflict of Interest Statement \\ None.}

First Received December 22, 2013; Final Revision received February 13, 2014; Accepted for publication March 11, 2014.

doi: 10.1111/ppc. 12070
PURPOSE: Explore the perceptions of nurses working in mental health of effective clinical leadership.

DESIGN AND METHODS: In-depth interviews were conducted with registered nurses employed in a mental health setting. Qualitative research using grounded theory.

FINDINGS: Remaining calm and confident in times of crisis and uncertainty was identified as one attribute of clinical leadership. Participants noted clinical leaders' demeanor during stressful or crisis situations, and their ability to manage unpredictable or unexpected clinical situations as contributing positively to clinical practice. PRACTICE IMPLICATIONS: Understanding these characteristics and how they can influence positive outcomes for clients is crucial in addressing the recruitment and retention challenges for the nursing workforce.
Nursing is a stressful and challenging area of work (Hamaideh \& Ammouri, 2011) and it is one of the few caring professions that provide hands-on care $24 \mathrm{hr}$ a day 7 days a week (Cleary, Hunt, Horsfall, \& Deacon, 2012; Deacon, Warne, \& McAndrew, 2006). This may mean that nurses are more likely than other health professionals who tend to work specified hours to encounter unplanned or unexpected situations (Cleary, Hunt, Horsfall, \& Deacon, 2011; Cleary et al., 2012).

Nursing environments that are unpredictable, such as emergency departments, intensive care units, and acute mental health settings (Cleary et al., 2011,2012; Currid, 2008; Gillespie, Gates, \& Berry, 2013; Ngako, van Rensburg, \& Mataboge, 2012; Nooryan, Gaspryan, Sharif, \& Zoladl, 2011; Ward, 2011), require nurses to have specialist skills in their specialized area of nursing and to be confident in decisionmaking (Fry et al., 2013; Yang, Thompson, \& Bland, 2012). In a medical intensive care unit, for example, nurses will need to have expertise in a number of clinical procedures that are more common in that setting, such as assessing levels of con- sciousness (Chan \& Matter, 2013) or delirium monitoring (Balas et al., 2012). In emergency or crisis situations in mental health, these skills involve bringing a sense of calmness to an unpredictable situation (Cleary, 2003; Cleary et al., 2011, 2012; Deacon et al., 2006; Dickinson, Ramsdale, \& Speight, 2009).

In mental health environments, the issues that most often challenge nursing staff include acute psychotic symptoms, self-harm, and behavioral disturbances that can potentially lead to aggression (Cleary et al., 2011; Currid, 2008; Deacon et al., 2006; Edward, 2005; Ngako et al., 2012; Ward, 2011). Clients in acute mental health settings are often in crisis during the initial stages of contact with a service provider (Cleary et al., 2011; Ngako et al., 2012). The ability to help clients develop strategies to safely navigate in times of crisis is regarded as a core goal of mental health nursing and requires a specialized set of skills (Cleary et al., 2012; Currid, 2008; Deacon et al., 2006; Ward, 2011).

Clinical leadership is emerging as an important characteristic for nurses (Downey, Parslow, \& Smart, 2011; Ereh \& 
Beshel, 2011; Morton \& Hyrkas, 2012; Ribelin, 2003; Stanley, 2010). It reinforces the importance of delivering individualized evidence-based care to clients (Alleyne \& Jumaa, 2007). Research has demonstrated that clinical leadership can lead to improved outcomes and a more positive experience for consumers and contribute to the recruitment and retention of staff (Alleyne \& Jumaa, 2007; Cook, 2001; Ribelin, 2003).

In mental health, effective clinical leadership can also assist in recruiting to this field that has traditionally experienced difficulty in attracting new nurses. A significant factor influencing undergraduates' choices around mental health is the quality of their clinical placement. Effective clinical leaders in mental health nursing can facilitate a more positive environment (Gough \& Happell, 2009; Happell, 2008, 2009; Happell \& Gaskin, 2012; Henderson, Happell, \& Martin, 2007; Zilembo \& Monterosso, 2008), potentially contributing to students developing more positive attitudes to mental health nursing.

In light of the challenges facing mental health nursing, and limited research describing clinical leadership and the role it might play in addressing these challenges, the aim of this paper is to explore the perceptions of nurses working in mental health about the characteristics of effective clinical leaders. More specifically, the focus of this paper relates to the demeanor of clinical leaders and their ability to portray a sense of calmness and confidence.

\section{Method}

\section{Design}

The concept discussed in this paper emerged through a grounded theory with a broad aim to explore the concept of clinical leadership in mental health nursing. Grounded theory is a qualitative approach to research that allows the researcher to generate a substantive theory or general explanation of an interaction or action by viewing the process through the experiences of participants (Creswell, 2007). The "grounded" in grounded theory comes from the process of constant comparative analysis of the data as well as its coding and categorization. This allows any emergent theory to be grounded in the data (McCann \& Clarke, 2003a).

\section{Setting}

The study was conducted in a mental health service where nurses worked across community teams, an inpatient unit, and a dedicated crisis and mental health triage service. This setting was chosen because it has a staffing profile suitable to meet the criteria for selection of participants.

\section{Participants}

Participants were registered nurses practicing in a mental health setting who had worked in the service for at least 12 months. The observations, experiences, and views of this group were considered important for this study in relation to clinical leadership in mental health nursing. Staff employed in the service for 12 months or more were assumed to have insights on the study area as they would be aware of both informal and formal roles within a team or service. A total of 12 eligible participants were recruited.

\section{Procedure}

Data were collected through individual, audio-recorded, semistructured interviews. These audio recordings were subsequently transcribed verbatim. Participants were asked to identify nurses in mental health whom they currently worked with, and believed were effective clinical leaders. They were then asked to explain why they identified these particular staff and consider what it was about them that made them effective clinical leaders. The questions asked of the participants were aimed to develop an understanding of what they viewed as the characteristics or attributes of effective clinical leaders in mental health nursing and why they felt they were important.

\section{Ethics}

All of the participation in this study was voluntary and formal consent was obtained from each participant. The study was undertaken in line with the national statement of ethical research (National Health and Medical Research Council, 2007), with ethical approval obtained from both the mental health service and university human research ethics committee.

\section{Analysis}

The data were analyzed according to a grounded theory approach, retaining as much of the participants' own words and experiences as possible. From analysis and constant comparison of these data, remaining calm and confident in a variety of challenging clinical situations as a characteristic of clinical leaders emerged as a category. This process is in keeping with a grounded theory approach to data collection and analysis (Chen \& Boore, 2009; Creswell, 2007; McCann \& Clarke, 2003b; Strauss \& Corbin, 1998).

A review of the types of questions asked and the sample of participants was also undertaken. This is known as theoretical sampling (McCann \& Clarke, 2003c). Theoretical sampling started after the initial data were analyzed and compared. As this subcategory around calmness and confidence emerged, it was continuously reviewed to ensure that it was consistent with the data. Theoretical saturation (Chen \& Boore, 2009; McCann \& Clarke, 2003a) was reached after nine interviews with participants. This was confirmed after a further three participants were interviewed with no new themes or categories emerging. 


\section{Findings}

Calmness and confidence of clinical leaders emerged as one category from analysis of participant interviews and is the focus of this paper. The characteristics described by participants and the situations used to highlight the importance of being able to remain calm and confident reflect the value they attach to these attributes in a crisis or stressful situation. The examples participants used to highlight these attributes revolved around the demeanor of those they viewed as effective clinical leaders and their ability to manage unpredictable or unexpected situations.

The clinical situations described by participants related to managing challenging behaviors and responding to mental health clients who are acutely unwell. The findings presented here focus on the participants' views in regard to effective clinical leaders, more specifically their ability to manage unpredictable or unexpected clinical situations, and the demeanor of effective clinical leaders during stressful or crisis situations.

\section{The Demeanor of Effective Clinical Leaders During Stressful or Crisis Situations}

Participants identified that effective clinical leaders in mental health nursing have a general deportment of calmness and confidence in the clinical area and this demeanor had a positive effect on others, including staff and clients. For example:

Confident - confident, self-assured . . . a good sense of themselves. Very considered and calm and not buying into that expressed emotions, sort of, situation, but thinking about things in a systematic and well planned thought out structured sort of way, I guess. And you don't see them flustered...

\section{The Ability to Remain Calm was Linked with Clinical Competence}

... his skill and his knowledge base, and he's just steady all the way. And he doesn't fluster easily. I don't think I've ever seen him flustered.

Participants also recognized that this ability to remain calm allowed them to engage with others and deal with periods of increased activity:

People who just can do a lot of things and then they just step back and they're listening rather than being frazzled

This capacity to remain calm and confident can have a positive effect on others as one participant stated:

... the ability to not be flustered in this place, I think it's a skill in itself. And you see as people - when they act up, the stress is reflected all over their face, really. On really busy days, I think they just sort of do a bit of self-talking [chuckle] even, and try to get through and be calm with themselves around people as well.

and similarly:

... just their level of confidence, certainly that confidence seems to permeate to those around them. Their knowledge base, also their really good people skills.

Participants identified instances where this ability to remain calm during a crisis influenced clinical practice:

I think that's why people look up to them and respect them is because they're able to maintain calm in a crisis and to direct people and to make good judgment and good decisions...

Participants had also experienced undergraduate nurses arriving for placement feeling apprehensive and nervous. They believed that effective clinical leaders often demonstrated to undergraduates the value of a calm and confident approach in clinical practice:

They do a lot of work with them, especially the students. They come in green as grass and scared - a lot of them need to be comforted, reassured, build up their own confidence

This demeanor was perceived as particularly important in developing confidence in junior staff and undergraduate nursing students. Participants described clinical leaders as role modeling good clinical practice to students, and provided examples of how this had been done:

[students can] stand back and watch somebody negotiate with a distressed person and it makes an impact, it leaves an impression and you take a lot away with you. I've had a lot of students talk to me regarding that; they like to watch a good clinician work. They get a lot of feedback from it and a lot of mileage. So it's valuable.

\section{Ability to Manage Unpredictable or Unexpected Clinical Situations}

Participants identified crisis-driven or unpredictable situations where a clinical leader's ability to remain calm and confident made a difference to the overall outcome or experience for both staff and clients. In relation to managing unpredictability, the situations described related to clinical scenarios where aggression was a factor or incidents where clients were acutely unwell and very distressed. One participant described a calm and confident approach, combined with good interpersonal skills, helped to avoid escalation into an aggressive incident:

... they [clinical leaders] actually were really calm with them [consumers] and they were really quiet and they 
took them away from the environment that was a bit heady and sat down with them and engaged them.

Similarly:

... a patient is becoming aggressive and impulsive on the ward, most of the shift managers react the same way. Nice and quiet and calm, let staff know what they are doing.

The importance of well-developed interpersonal skills and the confidence to use them in a stressful situation is highlighted:

body language is really important and you've got to have confidence in your own abilities to convey that to a patient without them feeling bullied and harassed

This ability to remain calm and confident during difficult situations is reinforced in this description of how a clinical leader influences the response in an emergency situation:

... if there's an aggressive/violent incident or an emergency, they are the staff that really sort of slide into that management role, and start and direct people where to go and what to do.

\section{Discussion}

Participants in this study have described how effective clinical leaders in mental health nursing use a calm and confident approach in clinical situations. They have identified the impact this type of approach can have on clinical outcomes for clients and the positive influence that this can have on less experienced staff, including undergraduate students. The importance of confidence in clinical decision-making and remaining calm in a crisis or other unplanned events has been identified across a range of healthcare settings (Cleary et al., 2012; Yang, Williams, \& Fang, 2011; Yang et al., 2012). Research has clearly identified that this skill is important for mental health nurses (Cleary et al., 2011, 2012; Dickinson et al., 2009; Edward, 2005; Ngako et al., 2012), although not described specifically in relation to the qualities of clinical leadership.

The ability to remain calm in an emergency is seen as a core component of nursing interventions (Cleary et al., 2012; Connell Meehen, 2012). Although this ability is well described in the literature (Cleary et al., 2011; Deacon et al., 2006; Dickinson et al., 2009; Ngako et al., 2012), its relevance to clinical leadership in mental health nursing has not been previously identified. Mental health nurses in this study identified an ability to remain calm and confident in an emergency or crisis as one of the core skills of clinical leaders in mental health nursing. The participants described clinical situations where a calm and confident approach was actually part of the intervention that enabled a positive outcome for clients.
These views reflect the essence of clinical leadership, where clinical practice is at least equally important to leadership characteristics themselves. Ultimately through their own practice, clinical leaders can influence improved outcomes for consumers, thereby contributing to the evidence base on the importance of clinical leadership in nursing (Alleyne \& Jumaa, 2007; Zilembo \& Monterosso, 2008).

Although the range and types of crisis or emergency situations in mental health nursing are as varied as in other healthcare settings, the types of situations that participants in this study most clearly linked to the importance of remaining calm and confident related to dealing with aggression or the potential for violence. Participants in this study also mirrored some of the findings in other studies and identified that dealing with challenging behavior or aggression called for a particular approach and a defined set of skills (Dickinson et al., 2009). Effective interpersonal skills are an obvious prerequisite (Cleary et al., 2012; Dickinson et al., 2009) but do not give the full picture. The importance of a calm and confident demeanor when dealing with difficult situations is especially important in mental health, given the necessity of maintaining an effective therapeutic relationship with the client (Cleary et al., 2012).

The clinical leader in mental health nursing needs a high level of skill between maintaining a therapeutic relationship with the client and resolving a challenging situation, particularly when behavioral issues are involved (Cleary et al., 2012; Dickinson et al., 2009; Edward, 2005; Ward, 2011). The ability to remain calm and confident was described by participants in this study as a therapeutic intervention in itself. It can also positively impact on other less experienced staff, including undergraduate nurses, and help change their views and perspectives on mental health as a career pathway (Gough \& Happell, 2009; Happell, 2008, 2009; Zilembo \& Monterosso, 2008).

Understanding that this ability to remain calm and confident in a crisis is a core skill of clinical leaders in mental health nursing may be the first step in understanding how these skills are developed. While these clinical skills are less easily taught in simulations or classroom settings (Guise, Chambers, \& Valimaki, 2011), mental health nursing should start to consider how to develop this skill set in the next generation of clinical leaders. Recognizing the importance of these attributes is essential as a starting point.

\section{Limitations}

Although this study aimed to gain the observations and experiences of nurses working in a mental setting on clinical leadership, it is accepted that the sample of participants is small and from only one clinical setting. Therefore, they may not be representative of the broader views of nurses in mental health settings. 


\section{Conclusion}

The ability to remain calm and confident in an unpredictable or emergency situation is an attribute that most people would agree is important for many leadership roles. This ability takes on an increased level of importance in healthcare settings as it can influence outcomes for clients.

Mental health nursing relies heavily on the nurse's ability to form and maintain therapeutic alliances with clients. This alliance can be severely tested and challenged during times of crisis. The ability to maintain this relationship requires mental health nurses to work with a client to resolve a challenging situation and requires a high level of skill and experience. Nurses working in a mental health setting in this study identified that effective clinical leaders have the ability to work through unpredictable or crisis situation with clients in a calm and confident manner, minimizing the potential impact on damaging the therapeutic relationship.

\section{Implications for Nursing Practice}

This study brings significant new insights on the views of nurses working in mental health on how clinical leaders are seen to use calmness and confidence in a variety of clinical situations. An understanding of how these skills are developed and the positive impact that they can have on clinical outcomes for clients and the experience of undergraduate nursing students may influence future nursing training at both undergraduate and postgraduate levels. This is an area that requires further research and investigation.

\section{References}

Alleyne, J., \& Jumaa, M. O. (2007). Building the capacity for evidence-based clinical nursing leadership: The role of the executive co-coaching and group clinical supervision for quality patient services. Journal of Nursing Management, 15(2), 230-243.

Balas, M., Vasilevskis, E., Burke, W., Boehm, L., Pun, B., Olsen, K., ... Ely, E. (2012). Critical care nurses' role in implementing the "ABCDE Bundle" into practice. Critical Care Nurse, 32(2), 35-47. doi:10.4037/cnn2012229

Chan, M., \& Matter, I. (2013). Investigating nurses' knowledge, attitudes and self-confidence patterns to perform the conscious level assessment: A cluster analysis. International Journal of Nursing Practice, 19, 351-359. doi:10.1111/ijn.12077

Chen, H., \& Boore, J. (2009). Using a synthesised technique for grounded theory in nursing research. Journal of Clinical Nursing, 16(18), 2251-2260.

Cleary, M. (2003). The challenges of mental health care reform for contemporary mental health nursing practice: Relationships, power and control. International Journal of Mental Health Nursing, 12, 139-147.

Cleary, M., Hunt, G., Horsfall, J., \& Deacon, M. (2011).

Ethnographic research into nursing in acute adult mental health units: A review. Issues in Mental Health Nursing 32, 424-435. doi:10.3109/01612840.2011.563339

Cleary, M., Hunt, G., Horsfall, J., \& Deacon, M. (2012).

Nurse-patient interaction in acute adult inpatient mental health units: A review and synthesis of qualitative studies. Issues in Mental Health Nursing, 33, 66-79. doi:10.3109/01612840.2011.622428

Connell Meehen, T. (2012). The careful nursing philosophy and professional practice model. Journal of Clinical Nursing, 21, 2905-2916. doi:10.1111/j.1365-2702.2012.04214.x

Cook, M. J. (2001). The renaissance of clinical leadership. International Nursing Review, 48(1), 38-46.

Creswell, J. W. (2007). Qualitative inquiry and research design (2nd ed.). Thousand Oaks, CA: Sage.

Currid, T. J. (2008). The lived experience and meaning of stress in an acute mental health nurses. British Journal of Nursing, 17(14), 880-884.

Deacon, M., Warne, T., \& McAndrew, S. (2006). Closeness, chaos and crisis: The attractions of working in acute mental health care. Journal of Psychiatric and Mental Health Nursing, 13, 750-757.

Dickinson, T., Ramsdale, S., \& Speight, G. (2009). Managing aggression and violence using rapid tranquillisation. Nursing Standard, 24(7), 40-49.

Downey, M., Parslow, S., \& Smart, M. (2011). The hidden treasure in nursing leadership: Informal leaders. Journal of Nursing Management, 19(4), 517-521. doi:10.1111/j.1365-2834.2011.01253.x

Edward, K. (2005). The phenomenon of resilience in crisis care mental health clinicians. International Journal of Mental Health Nursing, 14, 142-148.

Ereh, C. E., \& Beshel, C. A. (2011). Leadership norms: Its importance, challenges, and the way forward for innovative educational systems in Nigeria. International Journal of Academic Research, 3(6), 32-35.

Fry, M., MacGregor, C., Ruperto, K., Jarrett, K., Wheeler, J., Fong, J., \& Fetchet, W. (2013). Nursing praxis, compassionate caring and interpersonal relations: An observational study. Australian Emergency Nursing, 16, 37-44.

Gillespie, L., Gates, D., \& Berry, P. (2013). Stressful incidents of physical violence against emergency nurses. Online Journal of Issues in Nursing, 18(1). doi:10.3912/OJIN.Vol18No01Man02

Gough, K., \& Happell, B. (2009). Undergraduate nursing students attitude to mental health nursing: A cluster analysis approach. Journal of Clinical Nursing, 18(22), 3155-3164. doi:10.1111/j.1365-2702.2008.02764.x

Guise, V., Chambers, M., \& Valimaki, M. (2011). What can virtual patient simulation offer mental health nursing education? Journal of Psychiatric and Mental Health Nursing, 19, 410-418. doi:10.1111/j.1365-2850.2011.01797.x

Hamaideh, S. H., \& Ammouri, A. (2011). Comparing Jordanian nurses' job stressors in stressful and non-stressful clinical areas. Contemporary Nurse, 37(2), 173-187.

Happell, B. (2008). The importance of clinical experience for mental health nursing - Part 1: Undergraduate nursing 
students' attitudes, preparedness and satisfaction. International Journal of Mental Health Nursing, 17, 326-332.

Happell, B. (2009). Influencing undergraduate nursing students' attitudes towards mental health nursing: Acknowledging the role of theory. Issues in Mental Health Nursing, 30, 39-46. doi:10.1080/01612840802557113

Happell, B., \& Gaskin, C. J. (2012). The attitudes of undergraduate nursing students towards mental health nursing: A systematic review. Journal of Clinical Nursing, 22, 148-158. doi:10.1111/jocn.12022

Henderson, S., Happell, B., \& Martin, T. (2007). Impact of theory and clinical placement on undergraduate students' mental health nursing knowledge, skills, and attitudes. International Journal of Mental Health Nursing, 16(2), 116-125. doi:10.1111/j.1447-0349.2007.00454.x

McCann, T., \& Clarke, E. (2003a). Grounded theory in nursing research: Part 1 - methodology. Nurse Researcher, 11(2), 7-18.

McCann, T., \& Clarke, E. (2003b). Grounded theory in nursing research: Part 2 - critique. Nurse Researcher, 11(2), 19-28.

McCann, T., \& Clarke, E. (2003c). Grounded theory in nursing research: Part 3 - application. Nurse Researcher, 11(2), 29-39.

Morton, J. L., \& Hyrkas, K. (2012). Management and leadership at the bedside. Journal of Nursing Management, 20(5), 579-581. doi:10.1111/j.1365-2834.2012.01476.x

National Health and Medical Research Council. (2007). National statement on ethical conduct in human research. Canberra, Australia: Author.

Ngako, J., van Rensburg, E., \& Mataboge, S. (2012). Psychiatric nurse practitioners' experience of working with mental health care users presenting with acute symptoms. Curationis, 35(1), 44-53. doi:10.4102/curationis.v35i1.44

Nooryan, K., Gaspryan, K., Sharif, F., \& Zoladl, M. (2011). The effect of teaching emotional intelligence (EI) items on job related stress in physicians and nurses working in ICU wards in hospital, Yerevan, Armenia. International Journal of Collaborative Research on Internal Medicine \& Public Health, 3(10), 704-713.

Ribelin, P. (2003). Retention reflects leadership style. Nursing Management, 34(8), 18-19.

Stanley, D. (2010). Multigenerational workforce issues and their implications for leadership in nursing. Journal of Nursing Management, 18(7), 846-852. doi:10.1111/j.1365-2834.2010.01158.x

Strauss, A., \& Corbin, J. (1998). Basics of qualitative research techniques and procedures for developing grounded theory (2nd ed.). Thousand Oaks, CA: Sage.

Ward, L. (2011). Mental health nursing and stress: Maintaining balance. International Journal of Mental Health Nursing, 20, 77-85. doi:10.1111/j.1447-0349.2010.00715.x

Yang, H., Williams, B., \& Fang, J. (2011). The contribution of high-fidelity simulation to nursing students' confidence and competence: A systematic review. International Nursing Review, 59(1), 26-33.

Yang, H., Thompson, C., \& Bland, M. (2012). The effect of clinical experience, judgement task difficulty and time pressure on nurses' confidence calibration in a high fidelity clinical simulation. BMC Medical Informatics and Decision Making, 12, 113-121. doi:10.1186/1472-6947-12-113

Zilembo, M., \& Monterosso, L. (2008). Nursing students' perception of desirable leadership qualities in nurse preceptors: A descriptive survey. Contemporary Nurse, 27(2), 194-206. 